\title{
39. HISTORY OF HYDROTHERMAL SEDIMENTATION AT THE EAST PACIFIC RISE, $19^{\circ} \mathrm{S}^{1}$
}

\author{
Mitchell W. Lyle, College of Oceanography, Oregon State University \\ Robert M. Owen, Department of Atmospheric and Oceanic Science, The University of Michigan \\ and \\ Margaret Leinen, Graduate School of Oceanography, The University of Rhode Island ${ }^{2}$
}

\begin{abstract}
The rate at which hydrothermal precipitates accumulate, as measured by the accumulation rate of manganese, can be used to identify periods of anomalous hydrothermal activity in the past. From a preliminary study of Sites 597 and 598 , four periods prior to $6 \mathrm{Ma}$ of anomalously high hydrothermal activity have been identified: 8.5 to $10.5 \mathrm{Ma}, 12$ to $16 \mathrm{Ma}, 17$ to $18 \mathrm{Ma}$, and 23-to-27 Ma. The 18-Ma anomaly is the largest and is associated with the jump in spreading from the fossil Mendoza Ridge to the East Pacific Rise, whereas the 23-to-27-Ma anomaly is correlated with the birth of the Galapagos Spreading Center and resultant ridge reorganization. The 12-to-16-Ma and 8.5-to-10.5-Ma anomalies are correlated with periods of anomalously high volcanism around the rim of the Pacific Basin and may be related to other periods of ridge reorganization along the East Pacific Rise. There is no apparent correlation between periods of fast spreading at $19^{\circ} \mathrm{S}$ and periods of high hydrothermal activity. We thus suggest that periods when hydrothermal activity and crustal alteration at mid-ocean ridges are the most pronounced may be periods of large-scale ridge reorganization.
\end{abstract}

\section{INTRODUCTION}

The sediments west of the East Pacific Rise (EPR) at $19^{\circ} \mathrm{S}$ are primarily mixtures of calcium carbonate and hydrothermal precipitates derived from ridge crest hot springs (see, e.g., Lyle, this volume).

Despite the large proportion of calcite in the Leg 92 sediments, the biogenic input of material is low. Calcite is a significant fraction of the sediments only because much of the region, unlike the North Pacific central gyre region, is above the calcite compensation depth. Sedimentation rates in the Leg 92 cores range from $1.5 \mathrm{~cm} /$ $10^{3}$ yr. to less than $0.01 \mathrm{~cm} / 10^{3} \mathrm{yr}$. (Knüttel, this volume; Table 1). The rates correlate with paleodepth and thus with calcite preservation in the sediment, with highest rates when sites were shallowest and calcite was best perserved (see also Rea and Leinen, this volume). Typical sedimentation rates in the region are as slow or slower than rates measured in the North Pacific gyre, despite the better preservation of calcite. Another indication of the lack of biogenic input is that the Leg 92 sediments lack opaline biogenic tests. Neither diatom frustules nor radiolarian tests were observed during smear slide analysis or during examination of coarse fractions sieved from core-catcher material.

The region also lacks large inputs of organic matter to the sediments, and thus the postdepositional modification of the sediments by early diagenesis is at a minimum. For example, Gieskes et al. (this volume) found no evidence for even reductive remobilization of manga-

\footnotetext{
${ }^{1}$ Leinen, M., Rea, D. K., et al., Init. Repts. DSDP, 92: Washington (U.S. Govt. Printing Office).

Addresses: (Lyle) College of Oceanography, Oregon State University, Corvallis, OR 97331; (Owen) Department of Atmospheric and Oceanic Science, The University of Michigan, Ann Arbor, MI 48109; (Leinen) Graduate School of Oceanography, The University of Rhode Island, Narragansett, RI 02882.
}

nese, the most redox sensitive of the common transition metals. The input of continental detritus is also very low. Bloomstine and Rea (this volume) have noted that the eolian detrital component has accumulated 1 to 2 orders of magnitude more slowly than in similar regions of the North Pacific gyre.

The drilling transect for Leg 92 was located at $19^{\circ} \mathrm{S}$ partly because of the large proportion of hydrothermal precipitates in the sediments of the region. Boström and Peterson's (1966) analysis of the sediments in the general vicinity provided the first chemical evidence of hydrothermal activity at mid-ocean ridge crests. Later studies (e.g., Cronan, 1973; Dymond, 1981) have shown that metalliferous sediments are common just above basaltic basement in DSDP cores and that the distribution and composition of these sediments suggest a large source at the EPR. From these studies it has become apparent that of the deposits associated with hydrothermal activity, metalliferous sediments are the most widespread; in the South Pacific, they extend hundreds of kilometers from the EPR crest. Very little is known about changes in the distribution of hydrothermal precipitates with time, however. The purpose of this study is to examine the history of hydrothermal sedimentation at the Leg 92 drill sites, to relate the accumulation of hydrothermal precipitates to the processes now occurring at the EPR crest, and to relate changes in hydrothermal accumulation to tectonic events in the eastern Pacific Ocean. We have confined our analysis to two of the Leg 92 sites, 597 and 598. Both of these sites are located in areas of subdued topography, and basement is covered with a typical pelagic drape of sediments. There is no evidence either through analysis of the seismic reflection records or through analysis of the cores themselves for ponding or the preferential deposition of sediments at either site. There is also no evidence for a local source of hydro- 
Table 1. Mass accumulation rate information for Leg 92 sites.

\begin{tabular}{ccccc}
$\begin{array}{c}\text { Sub- } \\
\text { bottom } \\
\text { depth } \\
(\mathrm{m})\end{array}$ & $\begin{array}{c}\text { Time } \\
(\mathrm{Ma})^{\mathrm{a}}\end{array}$ & $\begin{array}{c}\text { Linear } \\
\text { sedimentation } \\
(\mathrm{m} / \mathrm{m}, \mathrm{y} .)\end{array}$ & $\begin{array}{c}\text { Dry bulk } \\
\text { density } \\
\left(\mathrm{g} / \mathrm{cm}^{3}\right)^{\mathrm{b}}\end{array}$ & $\begin{array}{c}\text { Mass } \\
\text { accumulation } \\
\text { rate }\end{array}$ \\
\hline
\end{tabular}

Hole 597

$\begin{array}{cr}0-1.5 & 0-14.2 \\ 1.5-4.1 & 14.2-17.0 \\ 4.1-15.5 & 17.0-18.7 \\ 15.5-19.2 & 18.7-22.0 \\ 19.2-27.8 & 22.0-24.8 \\ 27.8-54.7 & 24.8-28.3\end{array}$

0.11
0.93
6.7
1.1
3.1
7.7

0.51
0.77
1.03
1.11
1.05
0.98

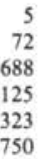

Hole 598

$\begin{array}{rr}0-1.0 & 0-1.9 \\ 1.0-4.7 & 1.9-5.4 \\ 4.7-6.4 & 5.4-6.7 \\ 6.4-9.0 & 6.7-8.1 \\ 9.0-12.4 & 8.1-9.2 \\ 12.4-16.0 & 9.2-10.7 \\ 16.0-17.0 & 10.7-12.0 \\ 17.0-29.7 & 12.0-14.2 \\ 29.7-52.4 & 14.2-17.0\end{array}$

0.53
1.05
1.31
1.86
3.09
2.40
0.77
5.77
8.11

0.60
0.67
0.89
0.85
0.85
0.89
0.84
0.73
0.67

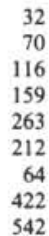

Hole 599

$$
\begin{array}{cr}
0-1.0 & 0-1.9 \\
1.0-2.8 & 1.9-3.7 \\
2.8-11.9 & 3.7-5.4 \\
11.9-30.8 & 5.4-6.7 \\
30.8-34.8 & 6.7-8.1
\end{array}
$$

$34.8-40.8 \quad 8.1-8.6$

$$
\begin{gathered}
0.53 \\
0.99 \\
5.35 \\
14.5 \\
2.86 \\
12.0
\end{gathered}
$$

this event has been preserved in the sediments of Hole 597. Rea (1981) has noted asymmetric spreading on a smaller scale in the $20^{\circ} \mathrm{S}$ area. He suggests that the spreading may have occurred either continuously or as many discrete westward rise jumps of only a few kilometers each.

\section{MODELING OF HYDROTHERMAL MANGANESE ACCUMULATION}

Since crustal heat loss by hydrothermal activity is primarily concentrated at rise crests, it is not surprising that hydrothermal sediments are also concentrated near the EPR crest. Figure 1 and Table 2 show the present accumulation pattern of manganese, one of the major components of the hydrothermal precipitates. The accumulation rate of hydrothermal precipitates decreases in a roughly exponential fashion away from the EPR crest; this distance effect must be taken into account when past hydrothermal activity at the rise crest is reconstructed from sediments that were deposited at some distance from the rise. Iron, the other major component of hydrothermal precipitates (Dymond, 1981), accumulates in a similar pattern away from the rise crest and can also be used to reconstruct past hydrothermal activity. We chose to use only manganese because there is no evidence of manganese remobilization in the sediments and because using iron produces the same trends (Table 2).

The pattern of hydrothermal accumulation is due to the combined effects of the injection into seawater of hydrothermal precipitates at hydrothermal vent areas, the slow horizontal transport of these precipitates by bottom currents away from the EPR crest, and precipitate settling. We used these parameters to model the rate of accumulation of hydrothermal manganese and other hydrothermal components as a function of distance from the EPR. In this model we assume that hydrothermal particles of a constant composition and grain-size distribution are injected into a hydrothermal plume at a height $I$ above the bottom. We then assume that the hydrothermal particles drift westward at a mean current velocity, $V$, normal to the EPR and settle to the bottom by Stokes law settling. To simplify the model, we ignore aggregation processes (which are discussed by McCave, 1984), resuspension processes, bottom boundary layer turbulence, and the change in depth of the bottom away from the rise crest. We also ignore ponding and other non-uniform sedimentation processes.

We assume that hydrothermal precipitates are injected to a height of approximately $200 \mathrm{~m}$ above the bottom, as has been observed in ${ }^{3} \mathrm{He}$ and manganese profiles at $21^{\circ} \mathrm{N}$ (Lupton et al., 1980) and in radon profiles and temperature anomalies at the Endeavour Ridge (Kadko and Lupton, 1984; Lupton and Delaney, 1984). We also assume that the grain-size distribution of the injected particles is log normal, as has been observed by Lambert et al. (1981), for all classes of sedimentary particles (including aluminosilicates, Fe-rich oxyhydroxides, and organic particles. Lambert et al. have formulated the log-normal distributions they observed as follows:

$\mathrm{d} N=\mathrm{d} D \frac{N}{\sigma \sqrt{2 \pi} D} \exp \left[-1 / 2\left(\frac{\ln D-\ln D m}{\sigma}\right)^{2}\right]$ 

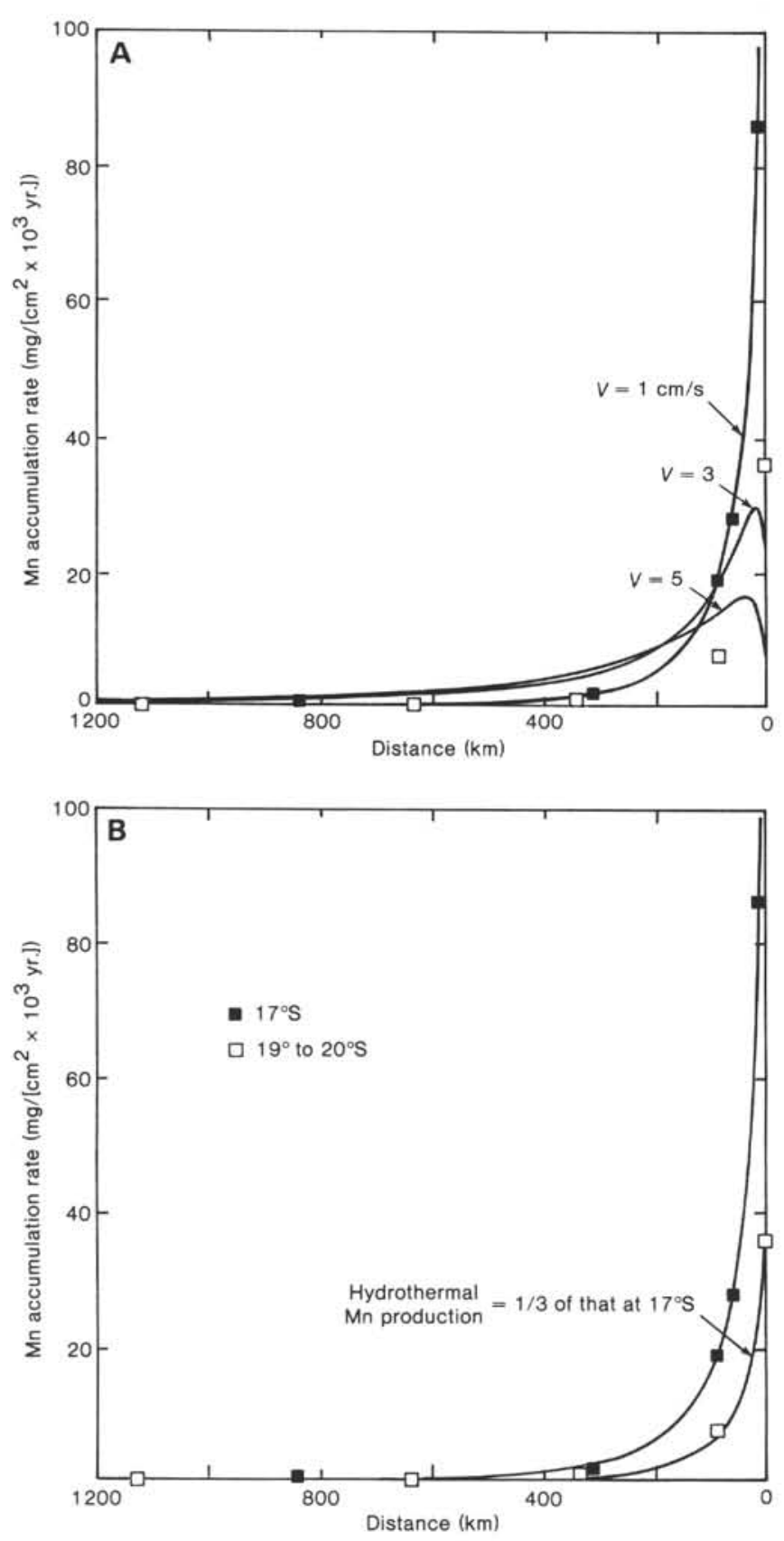

Figure 1. Accumulation rates of manganese in core tops from two transects of the East Pacific Rise at $17^{\circ}$ (filled squares) and at 19 to $20^{\circ} \mathrm{S}$ (open squares). Data are listed in Table 2. Figures $1 \mathrm{~A}$ and $1 \mathrm{~B}$ show attempts to fit both data sets by using the injection-settling model of hydrothermal accumulation developed in the text. The distribution of the hydrothermal particles injected is assumed to be log normal, and particles are assumed to have a median diameter of $2 \mu \mathrm{m}$, with a standard deviation of 0.65 . Figure $1 \mathrm{~A}$ attempts to fit both data sets by varying only the velocity of the current that carries the hydrothermal particles away from the rise crest. When near-crest accumulation rates fit, distal $\mathrm{Mn}$ accumulation rates are badly overestimated. Figure 1B attempts the fit by holding the velocity of the current constant at $1.3 \mathrm{~cm} / \mathrm{s}$ and varying hydrothermal activity at the rise crest. The two sets of data can be fit if hydrothermal activity (Mn production) at $19^{\circ}$ to $20^{\circ} \mathrm{S}$ is one-third the activity at $17^{\circ} \mathrm{S}$. where $D$ is particle diameter, $D m$ is median particle diameter, $N$ is the total number of particles, and $\sigma$ is the standard deviation about $\mathrm{Dm}$, in log units because of the style of formulation. Examples of the shape of this grain-size distribution for different standard deviations are shown in Figure 2. Observed grain-size distributions for deep-sea particles have standard deviations that range from 0.23 for organic particles to 0.71 for aluminosilicates (Lambert et al., 1981). We have chosen in our modeling to hold this parameter constant at 0.65 , a value similar to that observed for grain-size distributions for aluminosilicates and $\mathrm{Fe}$-rich oxyhydroxide particles.

We have also assumed that particulate hydrothermal material settles from the plume by Stokes law settling, according to which the vertical (settling) velocity of a particle is proportional to the square of its diameter. The time that a hydrothermal particle takes to settle to the sediment from a hydrothermal plume can thus be calculated from its injection height and grain diameter, and the distance that the particle has traveled normal to the ridge before settling on the bottom can be calculated by accounting for mean current velocity as follows:

$$
\text { Dist }=\frac{V I}{K D^{2}}
$$

where Dist is the distance normal to the rise crest, $I$ is the injection height, $V$ is the current velocity normal to the rise crest, $D$ is grain diameter, and $K$ is the Stokes constant. The Stokes constant is $(g / 18 \nu) \cdot[(\rho g-\rho w) /$ $\rho w]$, where $g$ is gravitational acceleration, $\nu$ is the dynamic viscosity of seawater at the temperature of bottom water, and $\rho g$ and $\rho w$ are the densities of the grain and of water, respectively.

The mass of hydrothermal particles sedimented as a function of distance from the rise crest can also be calculated for different mean current velocities through the use of equations (1) and (2) and by multiplying the number of particles deposited at a given distance by their volume and density:

$$
\text { Mass }=\left(\frac{\pi}{6} D^{3}\right) \rho g \mathrm{~d} N
$$

where $D$ is the mean diameter of particles deposited at some distance interval from the rise crest (equation 2), $\rho g$ is the grain density of the hydrothermal particles, and $d N$ is the number of particles deposited in the distance interval from a combination of equations (1) and (2). Mass per unit time or the accumulation rate of particles can be calculated if the rate of production of particles is assumed or fit to measurements. The accumulation rate of a hydrothermal element, such as manganese, can also be calculated if the concentration of the element in a hydrothermal particle is known.

Figure 1 shows typical results of the modeling for mean current velocities between 1 and $5 \mathrm{~cm} / \mathrm{s}$ and a median grain size of $2 \mu \mathrm{m}$. We chose this range of current velocities because it includes the velocities that are considered to be typical of the deep Pacific Basin on the basis of 
Table 2. Present manganese accumulation rates at the East Pacific Rise, $17^{\circ} \mathrm{S}$ and 19 to $20^{\circ} \mathrm{S}$.

\begin{tabular}{|c|c|c|c|c|c|}
\hline Core/Site & $\begin{array}{l}\text { Latitude } \\
\text { (S) }\end{array}$ & $\begin{array}{l}\text { Longitude } \\
\text { (W) }\end{array}$ & $\begin{array}{l}\text { Distance from } \\
\text { rise crest } \\
(\mathrm{km})^{\mathrm{a}}\end{array}$ & $\begin{array}{c}\text { Manganese } \\
\text { accumulation } \\
\text { rate } \\
\left(\mathrm{mg} /\left[\mathrm{cm}^{2} \times 10^{3} \mathrm{yr} .\right]\right)\end{array}$ & $\begin{array}{c}\text { Iron } \\
\text { accumulation } \\
\text { rate } \\
\left(\mathrm{mg} /\left[\mathrm{cm}^{2} \times 10^{3} \mathrm{yr} .\right]\right)\end{array}$ \\
\hline \multicolumn{6}{|l|}{$17^{\circ} \mathrm{S}$ transect } \\
\hline 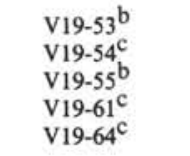 & $\begin{array}{l}17^{\circ} 01^{\circ} \\
17^{\circ} 02^{\prime} \\
17^{\circ} 00^{\circ} \\
16^{\circ} 57^{\prime} \\
16^{\circ} 56^{\circ}\end{array}$ & $\begin{array}{l}113^{\circ} 31^{\prime} \\
113^{\circ} 54^{\prime} \\
114^{\circ} 11^{\prime} \\
116^{\circ} 18^{\prime} \\
121^{\circ} 21^{\circ}\end{array}$ & $\begin{array}{r}19 \\
61 \\
88 \\
310 \\
840\end{array}$ & $\begin{array}{l}86 \\
28 \\
19 \\
2.0 \\
0.63\end{array}$ & $\begin{array}{c}240 \\
82 \\
73 \\
10 \\
3.8\end{array}$ \\
\hline \multicolumn{6}{|c|}{$19^{\circ}$ to $20^{\circ} \mathrm{S}$ transect } \\
\hline $\begin{array}{l}\text { OC73-3-20P }{ }^{\mathrm{d}} \\
\text { OC73-3-25P } \\
\text { Site } 600 \\
\text { Site } 599 \\
\text { Site } 598\end{array}$ & $\begin{array}{l}19^{\circ} 15^{\prime} \\
20^{\circ} 00^{\prime} \\
18^{\circ} 56^{\prime} \\
19^{\circ} 27^{\prime} \\
19^{\circ} 00^{\prime}\end{array}$ & $\begin{array}{l}113^{\circ} 35^{\prime} \\
114^{\circ} 31^{\prime} \\
116^{\circ} 51^{\prime} \\
119^{\circ} 53^{\circ} \\
124^{\circ} 41^{\circ}\end{array}$ & $\begin{array}{r}5 \\
87 \\
340 \\
640 \\
1130\end{array}$ & $\begin{array}{l}36 \\
7.7 \\
1.2 \\
0.41 \\
0.20\end{array}$ & $\begin{array}{c}120 \\
22 \\
3.4 \\
2.4 \\
0.68\end{array}$ \\
\hline
\end{tabular}

a Error in distance, $\pm 20 \mathrm{~km}$.

b Determined from sedimentation rates in Moser (1979) and elemental analyses in Dymond (1981).

c From Dymond and Veeh (1975).

${ }^{d}$ From Moser (1979).

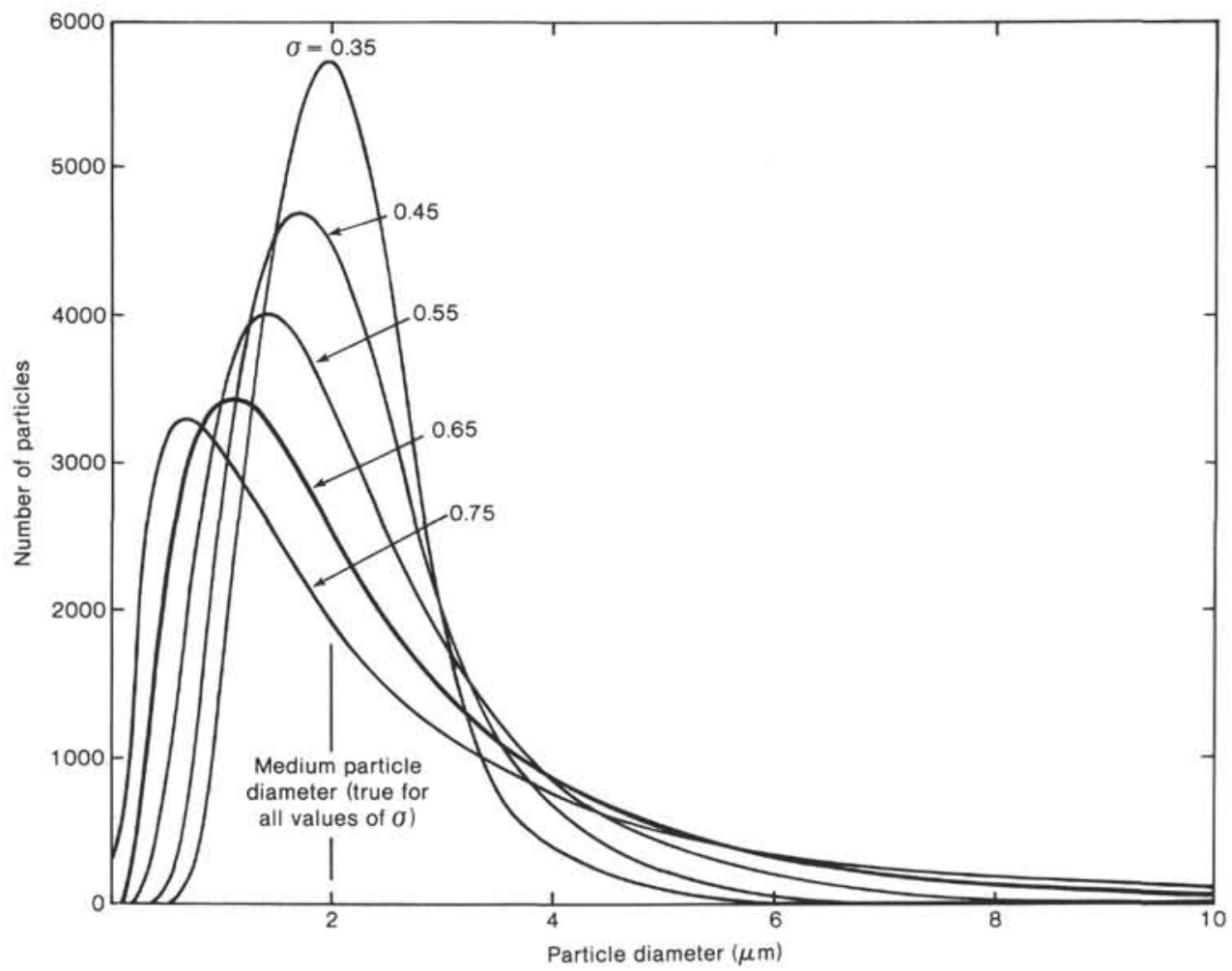

Figure 2. Log-normal particle distributions. The median particle diameter is $2 \mu \mathrm{m}$ in each, but the standard deviation of particle size varies. We used the $0.65 \sigma$ curve for the modeling shown in Figure 1 .

the MANOP project's 3-year-long. records of near-bottom current velocities (Fischer, 1984, for MANOP sites $\mathrm{M}$ and $\mathrm{H}$; J. Dymond, unpubl. data for MANOP Site C). The (directionless) mean velocity in each of the three records we inspected was 4 to $6 \mathrm{~cm} / \mathrm{s}$, near the upper range of the mean velocities we used in the model. Because bottom currents rarely travel in a constant direction, the long-term mean velocity in one direction is much lower than the directionless velocity. Even for a re- cord where the current is relatively constant, as pictured in the record from the EPR at $9^{\circ} \mathrm{N}$ (MANOP Site $\mathrm{M}$, Fig. 3), the mean velocity in the direction of most consistent flow is only $1.8 \mathrm{~cm} / \mathrm{s}$, as compared with $4.1 \mathrm{~cm} / \mathrm{s}$ for the directionless flow. The other two current records had even lower velocities along the direction of most common flow and were less than $1 \mathrm{~cm} / \mathrm{s}$ on the average.

From the simple theory of hydrothermal sedimentation we have outlined here, we can obtain, from a rela- 


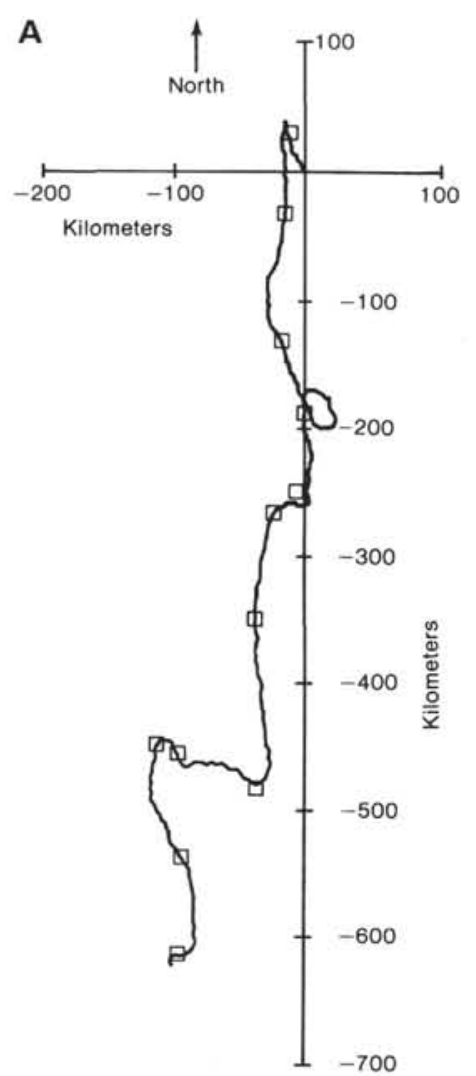

B

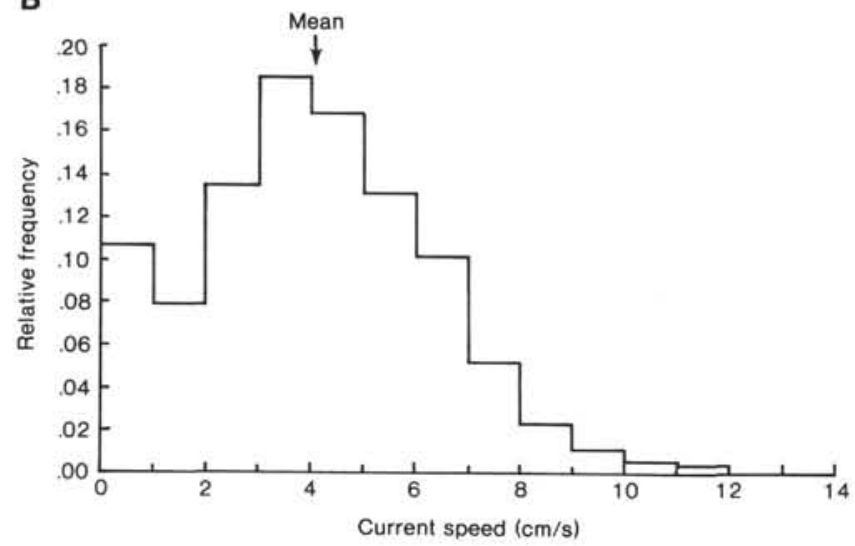

Figure 3. A. Summed vector diagram of currents $200 \mathrm{~m}$ above the bottom at MANOP Site $\mathrm{M}\left(8^{\circ} 45^{\prime} \mathrm{N}, 104^{\circ} \mathrm{W} ; 3100 \mathrm{~m}\right.$ water depth; 10 Sept. 1980 to 18 Oct. 1981). B. Frequency histogram of current speeds. The figure illustrates that although the average velocity of the bottom current may be relatively fast (here $4.1 \mathrm{~cm} / \mathrm{s}$ ), the velocity measured in one particular direction may be much slower. In this case, the mean velocity in the direction of maximum travel is only $1.8 \mathrm{~cm} / \mathrm{s}$.

tively small amount of data, large amounts of information about hydrothermal production, the median grain size of the hydrothermal particulates, and mean current velocity. For example, Figure 4 shows an attempt to fit measured Mn accumulation rate profiles at $17^{\circ} \mathrm{S}$ and 19 to $20^{\circ} \mathrm{S}$ by using a median grain diameter of $6 \mu \mathrm{m}$, while varying the mean current velocity between 1 and $5 \mathrm{~cm} / \mathrm{s}$. As can be seen from the figure, it is impossible to fit both near-crest and distal accumulation rate data with this particular grain size by using this size distribution.

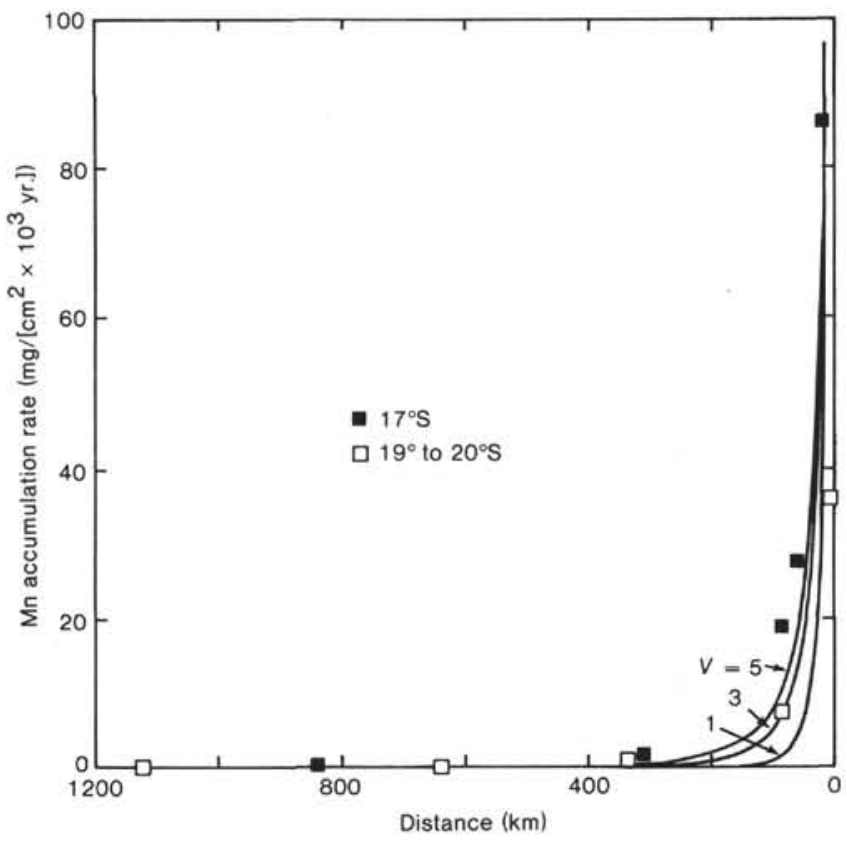

Figure 4. Result of attempting to fit measured manganese accumulation rates at $17^{\circ} \mathrm{S}$ and 19 to $20^{\circ} \mathrm{S}$ by assuming a log-normal particle size distribution for a median particle diameter of $6 \mu \mathrm{m}$ and a standard deviation of 0.65 . Particle size distributions for which median particle diameter is greater than $2 \mu \mathrm{m}$ fit the observed profiles poorly.

Either the near-crest accumulation rates are severely overestimated, or the Mn accumulation rates in the distal tail are severely underestimated by using this median diameter. After a series of tests, including tests of the effects of changing the magnitude of the standard deviation of the particle distribution upon the accumulation rate pattern, we have concluded that a hydrothermal particle distribution with a median grain size of $2 \mu \mathrm{m}$ and a standard deviation of 0.65 best fits the observed accumulation rate data (Fig. 1). The larger the median grain size of the particles, the greater the proportion of the total mass in quickly falling larger-diameter particles, because there are more large particles and because the mass carried in each particle increases as the cube of the particle size. If one attempts to fit the accumulation rate distribution with distance from the rise crest, median grain sizes greater than about $2 \mu \mathrm{m}$ lead to either large overestimates of the Mn accumulation rate near the rise crest, large underestimates of the Mn accumulation rate away from the rise crest, or unreasonably fast bottom currents to achieve the proper accumulation rate distribution. In a similar fashion, increasing the standard deviation of the particle distribution overconcentrates the accumulation of manganese near the rise crest, because the total number of large high mass particles increases significantly.

One of the greatest difficulties about fitting theoretical curves to the measured Mn accumulation rate data has been that the two different transects of the EPR reveal different patterns of manganese accumulation (Fig. 1, Table 2). Figure 1 illustrates the problem. The $17^{\circ} \mathrm{S}$ data have been fitted to a theoretical curve with a mean 
current velocity of $1 \mathrm{~cm} / \mathrm{s}$ and a $2-\mu \mathrm{m}$ median particle diameter. Although the $17^{\circ} \mathrm{S}$ data are fit very well, the data from 19 to $20^{\circ} \mathrm{S}$ are fit poorly. If the initially injected hydrothermal particulate material has the same size distribution everywhere, either current speed or the hydrothermal output of manganese must change between $17^{\circ}$ and $19^{\circ} \mathrm{S}$. An increase in mean current velocity to about $2.5 \mathrm{~cm} / \mathrm{s}$ between $17^{\circ}$ and $19^{\circ} \mathrm{S}$ could lower the accumulation rate sufficiently at the rise crest (Fig. 1A), but because the mass of hydrothermal material being produced at the rise crest remains the same, larger amounts of manganese must be deposited away from the rise crest. A current velocity sufficient to lower the Mn accumulation rate to the observed rate at the rise crest thus leads to an overestimate of $\mathrm{Mn}$ accumulation rate by a factor of almost 4 at a distance of $340 \mathrm{~km}$ from the rise (4.1 $\mathrm{mg} /\left[\mathrm{cm}^{2} \times 10^{3} \mathrm{yr}\right.$.] estimated vs. 1.2 observed). Figure $1 \mathrm{~B}$ shows the fit of the two profiles that results by assuming a constant current speed of $1.3 \mathrm{~cm} / \mathrm{s}$ in both transects and by assuming that the hydrothermal discharge of particulates (and presumably the discharge of hydrothermal fluid) at $17^{\circ} \mathrm{S}$ is a factor of 3 greater than at 19 to $20^{\circ} \mathrm{S}$. The fit for both profiles is very good, and the quality of the fit suggests that significant variations of hydrothermal output occur along strike at the EPR. Although there are no other estimates for hydrothermal activity in these two regions, we point out that the rise crest at $17^{\circ} \mathrm{S}$ is significantly broader and more shallow than at $19^{\circ} \mathrm{S}$, as one would expect in a region of more volcanic activity and higher hydrothermal activity.

We can thus explain the pattern of Mn accumulation rate with increasing distance from the EPR, provided that the median grain size of the hydrothermal particles is small $(\approx 2 \mu \mathrm{m})$, the grain-size distribution is log normal, and the mean current between $17^{\circ}$ and $20^{\circ} \mathrm{S}$ flows west at about $1 \mathrm{~cm} / \mathrm{s}$. Although there are no published studies of particle size distributions of hydrothermal particles to test the model, there is evidence of hydrothermal flow westward from the EPR at these latitudes.

By studying mantle-derived ${ }^{3} \mathrm{He}$, Lupton and Craig (1981) have discovered the existence of a hydrothermal plume in the vicinity of $20^{\circ} \mathrm{S}$ that extends west of the EPR crest for over $1000 \mathrm{~km}$. The plume may define the region to which the transport of hydrothermal material is possible. Stommel (1982) suggested that the injection of hot hydrothermal waters may in itself drive the plume. $\mathrm{He}$ argues that a simple model shows that the injection of hydrothermal waters provides sufficient energy to generate a westward flow; the maximum flow is at $10^{\circ} \mathrm{S}$. The existence of the plume has also been confirmed by Reid (1982). He develops estimates based on temperature and salinity profiles that indicate that a westward geostrophic flow of 0.2 to $0.3 \mathrm{~cm} / \mathrm{s}$ (relative to the $3500-\mathrm{m}$ decibar surface) exists in the plume. He cautions, however, that the flow estimate is not very well constrained. If his velocity estimate is nearly correct, however, the median grain size of the hydrothermal particulate material may be significantly smaller than we estimate.

In the next sections of this paper we use the modeling we have developed of the present manganese accumulation rate-distance distribution to look for periods of anomalous manganese accumulation and anomalous hydrothermal activity in the past. We consider periods of anomalous manganese accumulation to be times when the manganese accumulation rate is either too high or too low to be explained by varying current velocity between 1 and $5 \mathrm{~cm} / \mathrm{s}$. We use as initial conditions the optimal fit particle size distribution $(2 \mu \mathrm{m}, \sigma=0.65)$ and the hydrothermal output at $20^{\circ} \mathrm{S}$ (see Fig. 1).

\section{THE RECORD OF THE MENDOZA RISE-EAST PACIFIC RISE JUMP AT SITE 597}

Site 597 is the only one of the Leg 92 coring sites that is located on crust formed at a fossil spreading center. It is thus the only Leg 92 site that could possibly record the rise jump from the Mendoza Rise to the East Pacific Rise.

Figure 5 is an illustration of the variation with age of the manganese accumulation rate at Site 597. Manganese accumulation rates were determined by combining the linear sedimentation rates from Knüttel (this volume), the dry bulk densities estimated from shipboard measurements of physical properties (Table 1), and the major element compositions reported in Lyle (this volume). The distances of Site 597 from the rise crest through time were calculated from the spreading rates for the EPR-Mendoza Rise at $19^{\circ} \mathrm{S}$ (reported in Rea and Leinen, this volume). Since, as it ages, each DSDP site moves away from the rise crest where it was produced, one would expect the pattern of change in manganese accumulation rates upcore to resemble the modern pattern of change in accumulation rates with increasing distance from the EPR crest (Fig. 1). The oldest (basal) sediments should have the highest manganese accumulation rates, and the younger sediments (those deposited when the site lay farther from the rise crest) should have drastically lower Mn accumulation rates. With the exception of an age interval between 17 and $18.7 \mathrm{Ma}$, this is precisely the pattern observed at Site 597 (Fig. 5). The basal sediments have manganese accumulation rates of approximately $20 \mathrm{mg} /\left(\mathrm{cm}^{2} \times 10^{3} \mathrm{yr}\right.$.), and the rates decrease to about $5 \mathrm{mg} /\left(\mathrm{cm}^{2} \times 10^{3}\right.$ yr. $)$ by $24.7 \mathrm{Ma}$. At this time, Site 597 was at a distance from the Mendoza Rise crest of $200 \mathrm{~km}$ (a distance based upon the spreading rates estimated by Rea and Leinen [this volume] from magnetic anomalies). At distances greater than $500 \mathrm{~km}$ from the rise crest (ages less than about $19 \mathrm{Ma}$ ), the accumulation rate of manganese at Site 597 fell to less than $1 \mathrm{mg} /\left(\mathrm{cm}^{2} \times 10^{3} \mathrm{yr}\right.$. $)$.

During the time interval bounded by the $\mathrm{CN} 2$ nannofossil biostratigraphic Zone (17.0 to $18.7 \mathrm{Ma}$; Knüttel, this volume), the accumulation rate of manganese increased from these low background values to a peak of almost $20 \mathrm{mg} /\left(\mathrm{cm}^{2} \times 10^{3} \mathrm{yr}\right.$.). The timing of this event suggests that it may be correlated with the EPR rise jump at 18.5 Ma proposed by Mammerickx et al. (1980; see Fig. 6). We have sufficient evidence to show that the event is real and not a product of our data manipulation. Elemental accumulation rates, because they are derived by multiplying the average mass of sediments deposited in a time interval by the weight fraction of the element in the sediment, are very sensitive to errors in 


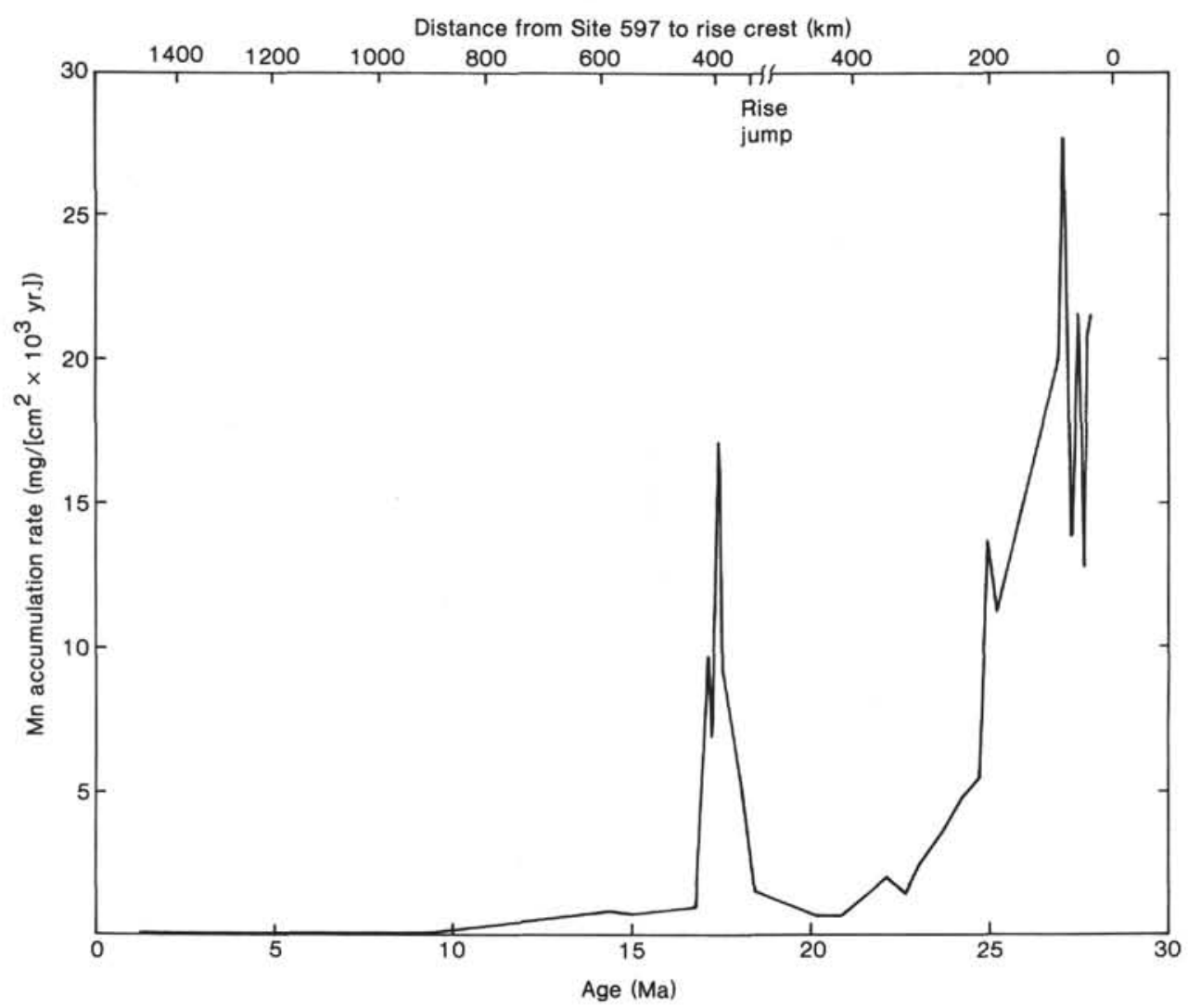

Figure 5. Manganese accumulation rates versus age (distance from the rise crest) at Site 597. The pattern of accumulation rate change with increasing distance from the rise crest is similar to the pattern that exists at present. In order to discern anomalous events, the typical decrease of manganese accumulation rate with distance from the rise crest must be removed.
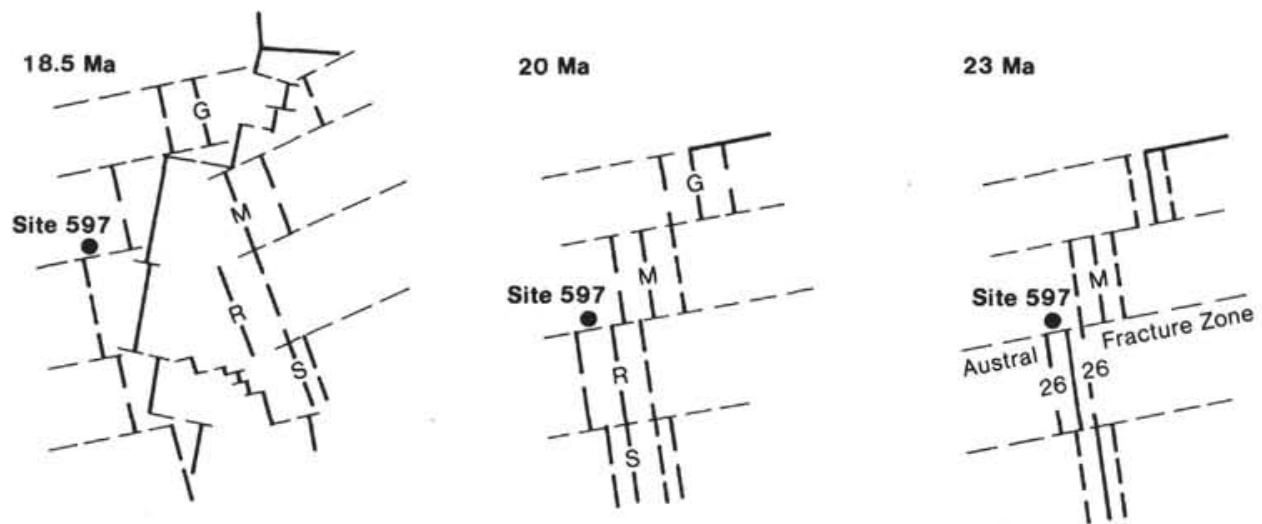

Figure 6. Mammerickx et al.'s (1980) interpretation of the tectonic history of the $19^{\circ} \mathrm{S}$ region between 23 and $18.5 \mathrm{Ma}$. Active spreading ridges are marked by heavy solid lines. Heavy dashed lines mark magnetic Anomaly 7 (26 Ma). The following abandoned spreading ridges are marked by letters: $\mathrm{G}=$ Gallego Rise; $\mathbf{M}=$ Mendoza Rise; $\mathbf{R}=$ Roggeveen Rise; $\mathbf{S}=$ Selkirk Rise.

the time scale. The interval from 17.0 to $18.7 \mathrm{Ma}$, which encloses the Mn spike, is marked by a seven- to tenfold increase in the total deposition of sediments as compared with the time intervals before and after it. Conceivably, then, there could be a major error in estimating the time interval boundary, and such an error could produce a spurious spike in $\mathrm{Mn}$ accumulation rate. Two lines of evidence show that the spike is not due to stratigraphic error, however. First, the peak accumulation rate of manganese is about 20 times as high as the Mn accumulation rates in the surrounding time intervals. This change in rate is at least 1 order of magnitude greater than the maximum possible time-scale-associated error. (The maximum possible error can be determined by assuming that the zone boundaries lie immediately adjacent to samples within the zone instead of placing the zone boundaries between samples.) Second, the sediment composition, which is independent of the time scale cho- 
sen, becomes more hydrothermal in character during this interval. As illustrated by the $\mathrm{Mn} / \mathrm{Al}$ ratio (Fig. 7), the Site 597 sediments become much more manganese rich at $18 \mathrm{Ma}$, a change that is consistent with the sediment's receiving a larger hydrothermal component at this time. The $\mathrm{Mn} / \mathrm{Al}$ ratio also decreased with time after about 17.5 Ma. This change can be interpreted either as the result of the site's moving farther away from a hydrothermal source or as a decrease of hydrothermal output from the two-ridge hydrothermal source region. In either case, the spike in Mn production is real, and it leads us to suggest that the EPR started producing crust at $19^{\circ} \mathrm{S}$ at about $18 \mathrm{Ma}$.

The magnitude of the 18-Ma spike is surprising, even when the rise jump is taken into account. Immediately before the jump in spreading to the EPR, Site 597 was approximately $550 \mathrm{~km}$ from a hydrothermal source at the Mendoza Rise, and it accumulated manganese at about the same rate as present-day sediments at an equivalent distance from the EPR $\left(0.5\right.$ to $1.0 \mathrm{mg} /\left[\mathrm{cm}^{2} \times 10^{3}\right.$ yr.]). The EPR started spreading $220 \mathrm{~km}$ to the west of the then-active Mendoza Rise (a distance based upon a comparison of the actual distance of Site 597 from the EPR and the distance to the Mendoza Rise crest determined by adding the spreading rates). Site 597 thus changed from being $550 \mathrm{~km}$ away from an active ridge crest to being $330 \mathrm{~km}$ away. If we use the present-day Mn accumulation rates as an indication of what the Mn accumulation rate profile at $18 \mathrm{Ma}$ should be, manganese accumulation should have increased as a result of the rise jump by a factor between 2 and 4 , the spread being dependent on the current speed. Even if both ridges were active during the jump, the accumulation rate should have increased by only a factor between 3 and 6 . We make this estimate by adding the accumulation rate of

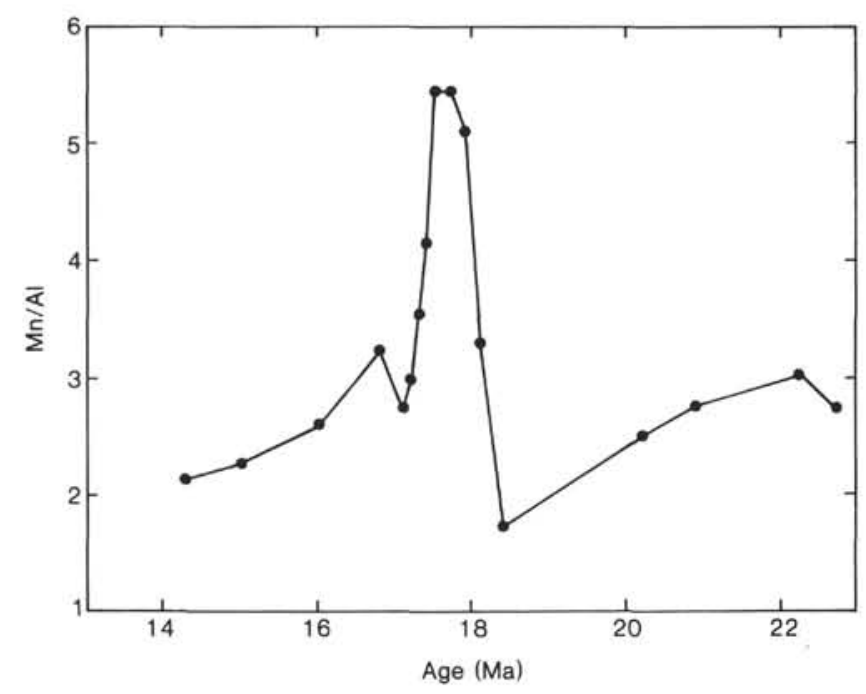

Figure 7. The 18-Ma Mn accumulation rate anomaly at Hole 597 also appears as an anomaly in sediment composition. The interval from 17 to $18 \mathrm{Ma}$ ( 4.8 to $11.3 \mathrm{~m}$ depth below surface) is much more hydrothermal in character (richer in Mn) than surrounding sediments (compositional data, Lyle, this volume). Thus, the accumulation rate anomaly cannot be due to error in the stratigraphic time scale. $\mathrm{Mn} / \mathrm{Al}$ is a weight ratio. manganese from the Mendoza Rise $550 \mathrm{~km}$ away to that for the newly formed EPR $330 \mathrm{~km}$ away and by assuming that the EPR and the Mendoza Rise had the same magnitude of hydrothermal activity. Instead, as pointed out earlier, the manganese accumulation rate increased by a factor of 20 . There was probably much more hydrothermal output from the ridge-crest region during the rise-jump time interval than is typical today at $19^{\circ} \mathrm{S}$. Volcanism and/or the exposure of seawater to hot rock in fractures and fissures must have been greater than today to increase hydrothermal input so much. If so, anomalies in volcanic output or in the extent of crustal alteration may be present in 18-Ma crust.

\section{OTHER HYDROTHERMAL ANOMALIES AT SITE 597}

In order to detect anomalies more subtle than the 18Ma event, we compared our model of the change in manganese accumulation rate with distance from the rise crest with the measured changes in accumulation rates (those that took place as the sites moved away from the ridge crest). The results are shown for Site 597 in Figure 8. We define as an anomaly any period of Mn accumulation that is too high or too low to be caused by changes in current velocity and express the anomaly as the ratio of the measured (past) rate of Mn accumulation to the modeled (present) rate. We point out as a warning, however, that the model of Mn accumulation has not yet been tested or constrained by measurements of typical hydrothermal particle size distributions or by measurements of bottom current velocities at $19^{\circ} \mathrm{S}$. Because of this, we ignore anomalies that occur in the long-distance tail of the accumulation rate profile (those indicated for distances farther than about $700 \mathrm{~km}$ from the site to the rise crest). This part of the profile is the most sensitive to errors in particle size distribution. We also vary the model current velocity between 1 and $5 \mathrm{~cm} / \mathrm{s}$ to reduce the chance that an anomaly is due to variations in bottom current velocity normal to the rise. We consider only events that are beyond the current-related range of manganese accumulation rates to represent true $\mathrm{Mn}$ anomalies.

During this analysis we have assumed that the current's direction has remained constant enough so that only one rise-crest hydrothermal source region has been sampled. By making this assumption we are also assuming that changes in $\mathrm{Mn}$ accumulation are due only to variations in hydrothermal activity within the source region; we are unable to identify or quantify changes in $\mathrm{Mn}$ accumulation rate that are due to variability in hydrothermal activity along strike at the rise crest. It is safe to assume that periods of anomalously high Mn accumulation rate cannot be due to activity at a radically different source region, since the farther away the alternative source is, the greater its hydrothermal activity must be even to match the non-anomalous $\mathrm{Mn}$ accumulation rate. However, if our modeling is correct, relatively large differences in hydrothermal activity exist even within about $250 \mathrm{~km}$ along the rise between $17^{\circ}$ and $19^{\circ} \mathrm{S}$. If these differences in hydrothermal activity existed in the past and if the direction of the current changed, some low- 


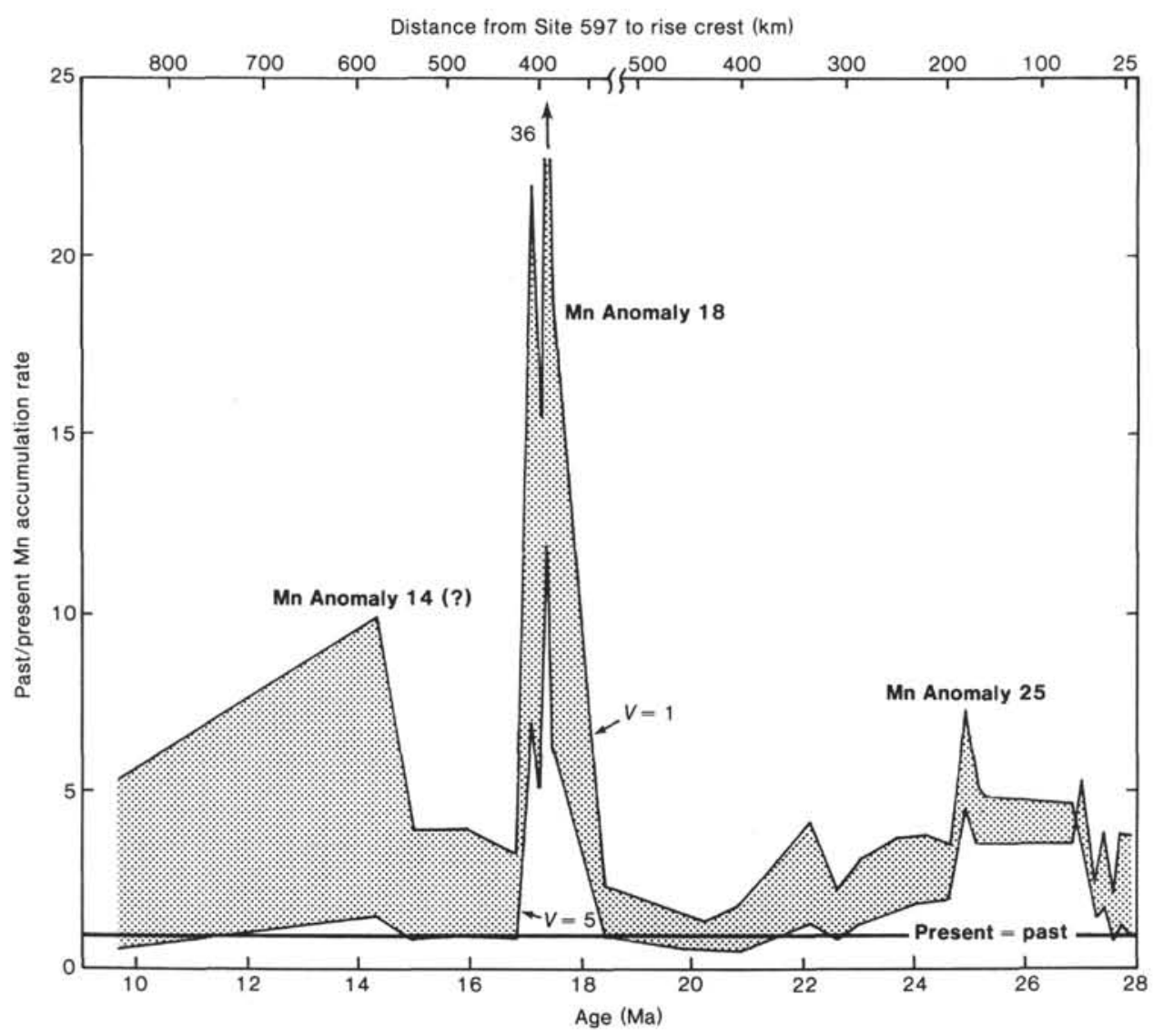

Figure 8. Anomalous manganese accumulation rates at Hole 597. The Mn accumulation rate observed in the core for a given distance from the rise crest is divided by the modeled present $\mathrm{Mn}$ accumulation rate calculated by assuming a constant hydrothermal output of manganese, a hydrothermal particle injection height of $200 \mathrm{~m}$, and a range of bottom current velocities normal to the rise crest ( $V$ ) of 1 to $5 \mathrm{~cm} /$ s. See the text and Fig. 1 for more information on the model. If the ratio of past rate to present rate is 1 (the line marked present $=$ past), hydrothermal manganese output was the same at that time as today. The stippled field marks the range of possible ratios of past to present accumulation rate, provided that current speeds are within the range of 1 to $5 \mathrm{~cm} / \mathrm{s}$. If this field lies completely above the line where the ratio is 1 , the $\mathrm{Mn}$ accumulation rate anomaly cannot be explained by changes in bottom current velocity and must be due to increased hydrothermal activity (increased hydrothermal Mn production) at the rise crest. The ratio of past to present $\mathrm{Mn}$ accumulation (the Mn anomaly) is equivalent to the ratio of past hydrothermal $\mathrm{Mn}$ production to the present.

amplitude anomalies might be due to changes in current direction instead of changes in the intensity of hydrothermal activity.

The analysis of hydrothermal anomalies at Site 597 is limited by the number of analyzed samples. Certain possible events, that for example at about $14 \mathrm{Ma}$ (Mn Anomaly 14), are too poorly constrained to be trusted from the Site 597 data alone. There is, however, one period of high hydrothermal activity other than the rise-jump time (Mn Anomaly 18, Fig. 8) that is defined by a sufficient number of samples so that it must represent an actual hydrothermal event. This is the period between approximately 23 and $27 \mathrm{Ma}$ (Mn Anomaly 25, Fig. 8). At its peak, the anomalous interval produced between 3 and 7 times the present hydrothermal manganese flux, according to our model.

\section{HYDROTHERMAL ANOMALIES AT SITE 598}

As at Hole 597, evidence for past hydrothermal events in Hole 598 is complicated by the decrease in hydrother- mal accumulation that occurs as the site moves away from the rise crest (Fig. 9). As Site 597, we compensated for the trend by calculating anomalous manganese accumulation rates (Fig. 10). As at Site 597, we ignored Mn accumulation rate anomalies in the long-distance tail of the accumulation rate profile, and again we defined anomalies as the intervals during which $\mathrm{Mn}$ accumulation rates lay outside the range of rates predicted by our model for current velocities between 1 and $5 \mathrm{~cm} / \mathrm{s}$. We found two periods of anomalous hydrothermal manganese production by this analysis (Fig. 10). Between approximately 12 and $16 \mathrm{Ma}$, and peaking at $13.6 \mathrm{Ma}(\mathrm{Mn}$ Anomaly 14, Fig. 10), hydrothermal Mn production at the $19^{\circ}$ to $20^{\circ} \mathrm{S}$ segment of the EPR was approximately 3 to 6 times greater than at the same distance from the EPR at present. At its peak, production may have been as great as 10 times the present hydrothermal production at the same distance. This anomaly in hydrothermal manganese production occurs at the same time as the questionable Mn Anomaly 14 in Hole 597 but is much better defined by 


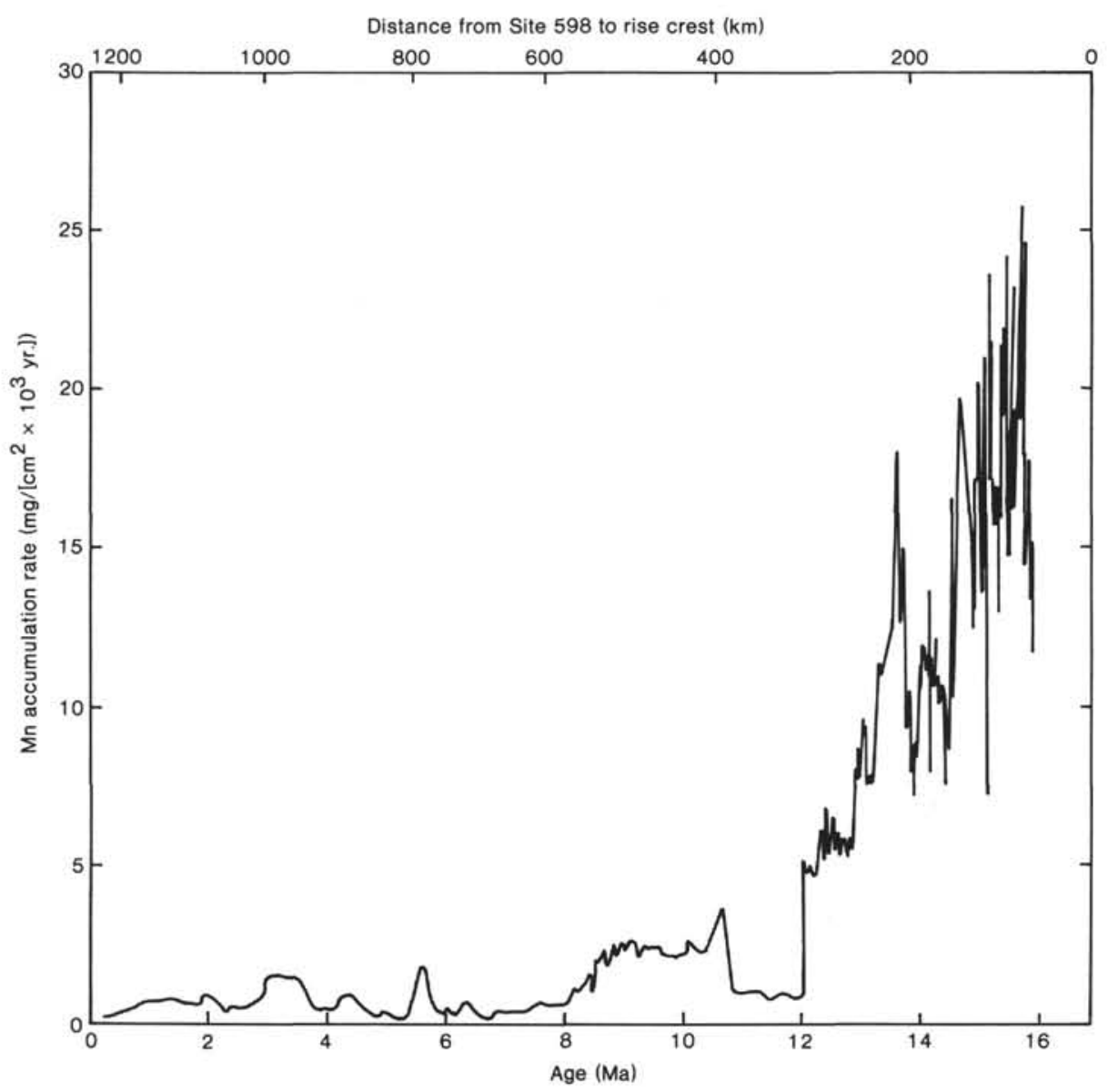

Figure 9. Manganese accumulation rates versus age (distance from the rise crest) at Site 598 (see Fig. 5 caption).

the sampling. Almost 200 samples cover the interval in Hole 598 versus 3 in Hole 597.

The second period of anomalous hydrothermal manganese production occurs between 8.5 and $10.5 \mathrm{Ma}(\mathrm{Mn}$ Anomaly 9, Fig. 10). The boundaries of the anomaly are less certain than those for Mn Anomaly 14, both because it is defined by fewer samples (28) and because, as explained below, it is more sensitive to the model current velocity (the Mn was originally deposited farther away from the rise crest, i.e., the particle source).

The faster a current is, the farther from the rise crest the hydrothermal particles will travel before being deposited and the greater the $\mathrm{Mn}$ accumulation rate will be at distance from the axis. Because of this, the difference between the model Mn accumulation rates based upon $5 \mathrm{~cm} / \mathrm{s}$ and $1 \mathrm{~cm} / \mathrm{s}$ current velocities will increase with distance from the rise crest. True changes in hydrothermal production will thus be harder to separate from modeling uncertainties in sediment deposited far from the rise crest.

At the distances from the rise crest where Mn Anomaly 14 was deposited $(<300 \mathrm{~km})$, the range of estimates varies by a factor of 2.4 or less, whereas at the distances at which Mn Anomaly 9 was deposited (400 to $600 \mathrm{~km}$ ), the model manganese accumulation rate estimates vary by a factor between 3 and 4 . Since the Mn anomaly is the ratio of the observed (past) Mn accumulation rate to the model (present) accumulation rate, the amount of anomalous hydrothermal production is not as well constrained at the greater distances from the rise crest. Indications are that Mn Anomaly 9 was less intense than Mn Anomaly 14, however, with a peak hydrothermal production of less than 8 times that at present.

\section{SITE 597 AND 598 ANOMALIES: DISCUSSION}

In Holes 597 and 598 we observe four periods of anomalously high hydrothermal manganese production, which are presumably also periods of abnormally high convective heat loss at the rise crest. There is no evidence that the anomalous Mn production events correlate with spreading rate changes, that is, with anomalous heat input to the rise crest (Rea and Leinen, this volume). For example, there is no evidence for changes in spreading rate on the west flank of the EPR of similar magnitude to the Mn anomalies, nor is there any correlation between anomalously high Mn production events and times of anomalously fast spreading. Magnetic anomalies in this region between 12 and $26 \mathrm{Ma}$ are poorly defined (Handschumacher, 1976), however, so the lack of correlation may partly reflect the lack of data.

There seems to be a better correlation between periods of anomalous hydrothermal activity and periods of 


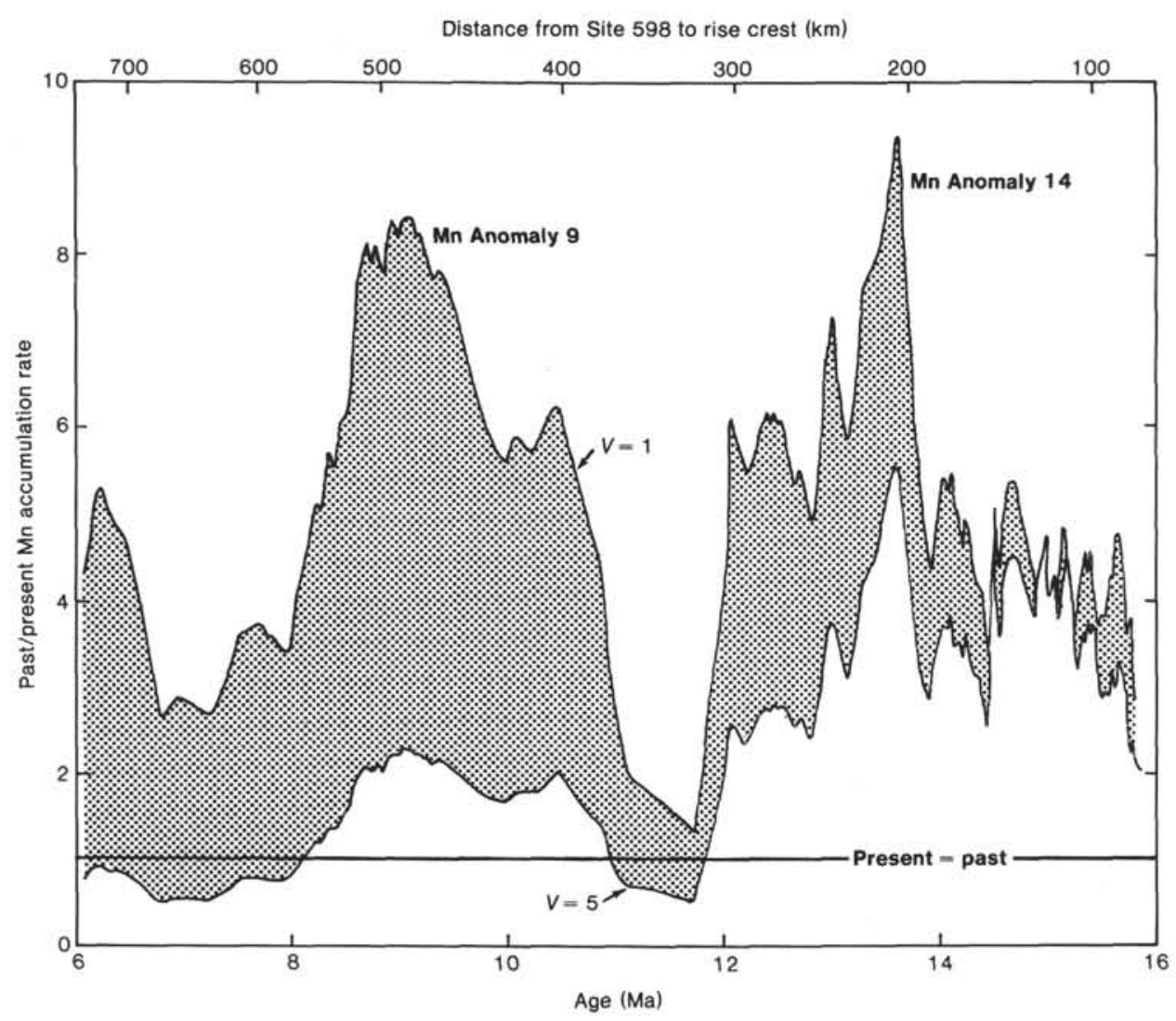

Figure 10. Anomalous manganese accumulation rates at Hole 598 (see Fig. 8 caption).

plate reorganization in the region, which presumably were accompanied by more exposure of hot rock by fracturing and faulting. As we have discussed in detail, Mn Anomaly 18 is correlated with the proposed MendozaEast Pacific Rise jump (Mammerickx et al., 1980). In addition, Mn Anomaly 25 correlates with the initial subduction of the Farallon Ridge under North America and the subsequent reorganization of spreading, including the initiation of spreading along the Galapagos Spreading Center (Handschumacher, 1976; Hey, 1977). Mn Anomaly 14 may correlate with another EPR plate reorganization at about the time of magnetic Anomaly 5A (12.5 Ma), which is best recognized in the northeast tropical Pacific (Mammerickx and Klitgord, 1982). Mn Anomaly 9 may be correlated with the reorientation event between 8 and 10.5 Ma marked by the change in strike of the Pacific-Rivera Ridge from north-northwest to northeast. Both of these correlations are tenuous, because little is known about how the EPR south of the equator responded to these reorientation events.

Each $\mathrm{Mn}$ production anomaly we observe is also correlated with episodes of synchronous circum-Pacific volcanism ( $\approx 25 \mathrm{Ma}, 16$ to $14 \mathrm{Ma}, 11$ to $8 \mathrm{Ma}, 6$ to $3 \mathrm{Ma}, 2$ to $0 \mathrm{Ma}$; Kennett et al., 1977; Rea and Leinen, this volume), and this correlation suggests that the anomalies may be related to Pacific-wide tectonic events and not to local anomalies in volcanic output. If the correlation between circum-Pacific volcanic events and $\mathrm{Mn}$ anomalies is valid, there should also be $\mathrm{Mn}$ anomalies in the time period between 3 and $6 \mathrm{Ma}$ and between $2 \mathrm{Ma}$ and some time before the present. Although we cannot resolve these time periods in Holes 597 and 598, we may be able to investigate this possibility more fully by making similar studies of the Site 600 and 601 sediments and by studying Site 599, provided that we can unravel the magnitude of sediment redeposition.

\section{CONCLUSIONS}

We observed four periods of anomalously high hydrothermal manganese production at the EPR at $19^{\circ} \mathrm{S}$. At Hole 598 we cannot reliably distinguish any event younger than about $6 \mathrm{Ma}$ but have detected Mn anomalies between 8.5 and $10.5 \mathrm{Ma}$ and 12 and $16 \mathrm{Ma}$. In Hole 597 we have detected anomalies at 17 to $18 \mathrm{Ma}$ and at 23 to $27 \mathrm{Ma}$, and we have observed a possible anomaly at $14 \mathrm{Ma}$ that is correlated to the record in Hole 598.

We propose that these $\mathrm{Mn}$ anomalies are correlated with periods of spreading reorientation at the EPR-Farallon Ridge system and are not correlated with spreading rate fluctuations. Accordingly, we predict that $\mathrm{Mn}$ anomalies will be found in the time intervals from 3 to $6 \mathrm{Ma}$ and from $2 \mathrm{Ma}$ to the present. This last hydrothermal event must also have ceased by Holocene time, or the modeling we have done would have detected significant negative anomalies in the past.

\section{REFERENCES}

Boström, K., and Peterson, M. N. A., 1966. Precipitates from hydrothermal exhalations on the East Pacific Rise. Econ. Geol., 61: $1258-1265$.

Cronan, D. S., 1973. Basal ferruginous sediments cored during Leg 16, Deep Sea Drilling Project. In van Andel, T. H., Heath, G. R., 
et al., Init. Repts. DSDP, 16: Washington (U.S. Govt. Printing Office), 601-604.

Dymond, J., 1981. Geochemistry of Nazca Plate surface sediments: an evaluation of hydrothermal, biogenic, detrital, and hydrogenous sources. In Kulm, L. D., Dymond, J., Dasch, E. J., Hussong, D. M., and Roderick, R. (Eds.), Nazca Plate: Crustal Formation and Andean Convergence. Mem. Geol. Soc. Am., 154: 133-174.

Dymond, J., and Veeh, H. H., 1975. Metal accumulation rates in the southeast Pacific and the origin of metalliferous sediments. Earth Planet. Sci. Lett., 28:13-22.

Fischer, K., 1984. Particle fluxes in the eastern tropical Pacific Oceansources and processes [Ph.D. dissert.]. Oregon State Univ., Corvallis.

Handschumacher, D. W., 1976. Post-Eocene plate tectonics of the eastern Pacific. In Sutton, G. H., Manghnani, M. H., Moberly, R., and McAfee, E. E. (Eds.), The Geophysics of the Pacific Ocean Basin and Its Margin. Monogr. Am. Geophys. Union, 19:177-202.

Handschumacher, D. W., Pilger, R. H., Jr., Foreman, J. A., and Campbell, J. F., 1981. Structure and evolution of the Easter Plate. In Kulm, L. D., Dymond, J., Dasch, E. J., Hussong, D. M., and Roderick, R. (Eds.), Nazca Plate: Crustal Formation and Andean Convergence. Mem. Geol. Soc. Am., 154:63-77.

Herron, E. L., 1972. Sea floor spreading and the Cenozoic history of the east-central Pacific. Geol. Soc. Am. Bull. . 83:1671-1692.

Hey, R., 1977. Tectonic evolution of the Cocos-Nazca spreading center. Geol. Soc. Am. Bull., 88:1404-1420.

Kadko, D., and Lupton, J. E., 1984. Radon-222 and temperature measurements on the Endeavour Ridge. EOS, Trans. Am. Geophys. Union, 65:974.

Kennett, J. P., McBirney, A. R., and Thunell, R. C., 1977. Episodes of Cenozoic volcanism in the circum-Pacific region. J. Volcan. Geotherm. Res., 2:145-163.

Lambert, C. E., Jehanno, C., Silverberg, N., Brun-Cottan, J. C., and Chesselet, R., 1981. Log-normal distributions of suspended particles in the open ocean. J. Mar. Res., 39:77-98.
Lupton, J. E., and Craig, H., 1981. A major helium-3 source at $15^{\circ} \mathrm{S}$ on the East Pacific Rise. Science, 214:13-18.

Lupton, J. E., and Delaney, J., 1984. Water column temperature anomalies near an active deep-sea hydrothermal vent. EOS, Trans. Am. Geophys. Union, 65:975.

Lupton, J. E., Klinkhammer, G. P., Normark, W. R., Haymon, R., MacDonald, K. C., Weiss, R. F., and Craig, H., 1980. Helium-3 and manganese at the $21^{\circ} \mathrm{N}$ East Pacific Rise hydrothermal site. Earth Planet. Sci. Lett., 50:115-127.

McCave, I. N., 1984. Size spectra and aggregation of suspended particles in the ocean. Deep Sea Res., 31:329-352.

Mammerickx, J., Herron, E., and Dorman, L., 1980. Evidence for two fossil spreading ridges in the southeast Pacific. Geol. Soc. Am. Bull., Pt. I, 91:263-271.

Mammerickx, J., and Klitgord, K. D., 1982. Northern East Pacific Rise: evolution from 25 m.y.B.P. to the present. J. Geophys. Res., 87:6751-6759.

Moser, J. C., 1979. Sedimentation and accumulation rates of Nazca Plate metalliferous sediments by high resolution $\mathrm{Ge}(\mathrm{Li})$ gammaray spectrometry of uranium series isotopes [MSci. thesis]. Oregon State University, Corvallis.

Rea, D. K., 1981. Tectonics of the Nazca-Pacific divergent plate boundary. In Kulm, L. D., Dymond, J., Dasch, E. J., Hussong, D. M., and Roderick, R. (Eds.), Nazca Plate: Crustal Formation and Andean Convergence. Mem. Geol. Soc. Am., 154:27-63.

Reid, J. L., 1982. Evidence of an effect of heat flux from the East Pacific Rise upon the characteristics of mid-depth waters. Geophys. Res. Lett., 9:381-384.

Stommel, H., 1982. Is the south Pacific helium-3 plume dynamically active? Earth Planet. Sci. Lett., 61:63-67.

Date of Initial Receipt: 30 July 1984 Date of Acceptance: 1 March 1985 